\title{
UTILIZAÇÃO DE FERRAMENTAS DIDÁTICAS NO ENSINO DE QUÍMICA VISANDO APRIMORAR O PROCESSO DE ENSINOAPRENDIZAGEM
}

\section{UTILIZATION OF DIDACTIC TOOLS IN CHEMISTRY TO ENHANCE THE TEACHING-LEARNING PROCESS}

\author{
Joab dos Santos Lima ${ }^{1}$; Márcio Jean Fernandes Tavares²; Vicente Maxim da Silva Araújo ${ }^{3}$; \\ Flávia Rhuana Pereira Sales ${ }^{4}$; Alessandra Marcone Tavares Alves de Figuerêdo ${ }^{5}$
}

\section{RESUMO}

Muitos estudantes apresentam falta de interesse na escola e nos estudos, tendo como causa diversos fatores que entre eles encontra-se a didática empregada pelo docente. Esse quadro é ainda mais alarmante quando abordamos as ciências exatas, principalmente, a disciplina de Química que apresenta conceitos e teorias abstratas. De acordo com o documento oficial PCNEM (Parâmetros Curriculares Nacionais para o Ensino Médio), todos os assuntos transmitidos em sala de aula devem ter uma abordagem contextualizada para que seja alcançada uma aprendizagem significativa, ou seja, os conceitos devem apresentar um valor relevante que favoreça a compreensão do mundo natural, social, político e econômico, enaltecendo a aplicabilidade dos mesmos na vida do alunado. Sendo assim, esse trabalho descreve os resultados de uma pesquisa desenvolvida para discentes do Ensino Médio, o qual foi baseado numa metodologia qualitativa de cunho participativo, e ainda apresentou uma abordagem quantitativa. $\mathrm{O}$ estudo foi direcionado para os conteúdos: misturas, solubilidade e separação de misturas, os quais foram explanados com o uso de diversas ferramentas didáticas, como a contextualização, problematização e experimentação, por meio de aulas expositivas dialogadas. Os resultados foram interpretados por meio de métodos qualitativos, os quais avaliam o conhecimento como um processo social, em que todos participam para sua construção através de sua realidade cotidiana, comportamento e postura empregada em sala, além de uma análise quantitativa, a qual avalia a progressão da aprendizagem de forma sistemática. Frente aos resultados analisados, pode-se afirmar que os instrumentos didáticos empregados possibilitaram a edificação de um conhecimento químico significativo, de modo que cada discente participou ativamente durante o processo de ensinoaprendizagem, percebendo a ciência inserida em seu dia a dia, o que o faz atuar criticamente frente as situações.

Palavras-Chave: Ensino de química, contextualização, experimentação, processo de ensino aprendizagem.

\begin{abstract}
Many students have a lack of interest in school and studies, due to several factors that include the didactics used by the teacher. This reality is even more alarming when we approach the exact sciences, mainly the discipline of Chemistry that presents concepts and abstract theories.According to the official document PCNEM (National Curriculum Parameters for High School), all subjects transmitted in the classroom should have a contextualized approach in order to achieve meaningful learning, which the concepts present a relevant value that

\footnotetext{
${ }^{1}$ Graduando do Curso de Licenciatura em Química, IFPB, joabsantoswieira@ gmail.com

${ }^{2}$ Graduando do Curso de Licenciatura em Química, IFPB, marciojeanftavares@gmail.com

${ }^{3}$ Mestrando em ensino das ciências, UFRPE, vicentemaxim@yahoo.com.br

${ }^{4}$ Mestranda em Química Analítica, UFPB, flavia.rhuana@ outlook.com

${ }^{5}$ Doutora em Química, IFPB, alessandratavaresfigueiredo@ifpb.edu.br
} 
favors the understanding of the natural world, social, political and economic, praising the applicability in the life of the student. Thus, this paper describes the results of a research developed for high school students, which was based on a qualitative methodology of participatory nature, and also presented a quantitative approach. The study was directed to the contents: mixtures, solubility and separation of mixtures, which were explained with the use of several didactic tools, such as contextualization, problematization and experimentation, through dialogic expository classes. The results were interpreted through qualitative methods, which evaluate knowledge as a social process, in which all participate for its construction through its daily reality, behavior and posture used in the classroom, also to a quantitative analysis, which evaluates the progression of learning in a systematic way. In view of the analyzed results, it can be stated that the didactic tools employed allowed the construction of a significant chemical knowledge, so that each student participated actively during the teachinglearning process, perceiving the science inserted in their daily life, which makes it the students act critically in the situations.

Keywords: Chemistry education, contextualization, experimentation, teaching-learning process.

\section{INTRODUÇÃO}

A maioria dos alunos do Ensino Médio apresenta dificuldade em compreender de maneira clara os assuntos relacionados à disciplina de Química, seja por sua complexidade e quantidade de teorias ou por falta de contextualização.

É de suma importância que o professor de Química tenha como prioridade, a busca de métodos inovadores que auxiliem a didática de ensino, visando instigar o interesse pela ciência, bem como solucionar alguns problemas relacionados à aprendizagem, uma vez que a prática regular do ensino de Química nas escolas públicas (metodologia tradicional) torna o papel do discente passivo em sala de aula, dificultando a construção de um conhecimento químico significativo.

Nesse sentido, uma das vertentes relevantes é a contextualização. Ao optar por uma aplicação de forma contextualizada, o docente deve relacionar os conceitos químicos à realidade dos discentes, de modo que eles possam identificar e compreender a Química presente em seu dia a dia.

Além disso, pode-se destacar a experimentação, pois esta ferramenta didática possibilita uma melhor compreensão e internalização dos conteúdos referente à disciplina de Química, promovendo uma melhor dinamização na explicação do conteúdo em estudo, bem como estimula a participação mais ativa do alunado, dado que os alunos interagem entre si, trocam ideias e conhecimentos sobre o tema exposto.

Diante do exposto, essa pesquisa buscou desenvolver aulas expositivas-dialogadas para o conteúdo de misturas e separação de misturas utilizando ferramentas didático- 
pedagógicas, tais como: contextualização e experimentação, com o intuito de aprimorar a interação aluno-professor viabilizando um melhor processo de ensinoaprendizagem. Através de avaliações sistemáticas e progressista com base em dados obtidos, foi possível verificar a contribuição cientifica e pessoal que as aulas não tradicionais puderam trazer para os indivíduos do colegiado.

\section{FUNDAMENTAÇÃO TEÓRICA}

O Ensino de Química tem se caracterizado por aulas quase que exclusivamente expositivas em que os conceitos químicos (metodologia tradicional), em que os discentes são meros receptores de informações sendo comum nas escolas. Freire (2011, p. 80) denomina essa prática como modelo bancário, no qual "a única margem de ação que se oferece aos educandos é a de receberem os depósitos, guardá-los e arquivá-los". Com isso, todo e qualquer conteúdo se resume às comprovações matemáticas, desvinculadas dos fenômenos que levaram à sua quantificação e das relações desses conceitos com situações reais do contexto socioeconômico e cultural no qual o indivíduo está inserido.

Segundo Oliveira e colaboradores(2010), o ensino de Química é, na maioria das vezes, enfatizado no aspecto representacional pela observação, compreensão e interpretação da teoria proposta, ou seja, é articulado por meio da memorização de conceitos desarticulados, proferindo falta de interesse por parte do alunado.

Logo, o ensino de Química deve ser ministrado de forma contextualizada, visto que a contextualização se trata da relação dos conceitos químicos com a vivência dos estudantes. De modo geral, o conhecimento empírico do alunado é relacionado aos conhecimentos científicos de tal modo que o discente possa perceber a ciência presente em seu dia a dia, facilitando a compreensão do conteúdo abordado.

Os Parâmetros Curriculares Nacionais para o Ensino Médio (PCNEM), propõem a contextualização para o ensino das disciplinas. Os PCNEM apontam que, partindo de estudos precedentes do cotidiano, o discente poderá construir e reconstruir conhecimentos que permitam uma leitura mais crítica do mundo físico e possibilitem tomar decisões fundamentadas em conhecimentos científicos, favorecendo o exercício da cidadania (BRASIL, 1999, p. 208).

Os Parâmetros Curriculares Nacionais ( $\mathrm{PCN}+)$ definem que as escolhas sobre o que ensinar devem ser pautadas pela seleção de conteúdos e temas relevantes que favoreçam a compreensão do mundo natural, social, político e econômico. E, para isso, a forma de tratamento desses temas e conteúdos é determinante e deve contemplar o desenvolvimento de 
procedimentos, atitudes e valores (BRASIL, 1999, p. 85).

Nesse sentido, o docente deve transmitir o conteúdo de forma contextualizada, envolvendo elementos necessários para que o discente compreenda os conceitos de Química aplicados em seu cotidiano, possibilitando uma formação mais adequada, por meio de ações e associações significativas que permitem internalizar o conhecimento químico e torna-lo associável aos diversos contextos do dia a dia. Em concernência, Luiz e Pacheco (1997, p. 37) afirmam que

pode-se considerar que o objetivo central do ensino de Química para formar o cidadão é preparar o indivíduo para que ele compreenda e faça uso das informações químicas básicas necessárias para sua participação efetiva na sociedade tecnológica em que vive. Neste sentido, o ensino levaria o aluno a compreender os fenômenos químicos mais diretamente ligados à sua vida cotidiana [...]

Dessa forma, utilizando como ferramenta integradora de ensino, as práticas experimentais contribuirão para que o alunado entenda cada fenômeno químico abordado, visto que é uma forma de despertar a curiosidade e um maior interesse, possibilitando promover investigações e discussões sobre o conteúdo.

Segundo Silva (2016, p.20), “a experimentação pode ser uma estratégia eficiente para a produção de explicações para problemas reais que permitam uma contextualização, e dessa maneira estimular questionamentos que encaminhem à investigação”.

Com isso, o docente deve proporcionar um ambiente participativo, em que ele seja o mediador das ações, atribuindo um papel ativo para o alunado. Para isso, é imprescindível que haja articulação da narrativa, dos meios a serem utilizados e das ações propostas, para que o conjunto viabilize a estruturação de um ambiente apropriado, de tal modo que o discente, por meio de sua participação e formulação de hipóteses possa edificar seu saber químico.

Dentro desse contexto, a utilização de recursos didáticos como a contextualização e a experimentação podem propiciar um processo de ensinoaprendizagem significativo. De acordo com Oliveira e colaboradores (2016), a edificação significativa de conhecimentos acontece quando os conceitos ensinados apresentam uma estrutura lógica e o significado é o produto da aprendizagem.

Uma das formas de oferecer essa diversidade é mostrar onde os processos de separação de misturas estão diretamente ligados ao nosso dia a dia e a nossa qualidade de vida, usando exemplos reais do contexto vivencial do colegiado, como por exemplo, demonstrar que tais processos estão ligados à fabricação de cachaça, no tratamento de água, no tratamento de esgoto, na dessalinização das águas, no café que preparamos, quando doamos sangue ou fazemos exames, na obtenção de novas substâncias para fazer 
medicamentos, dentre outros.

\section{METODOLOGIA}

Realizou-se uma pesquisa de cunho participativo aplicada com 25 (vinte e cinco) alunos do $1^{\circ}$ ano do Ensino Médio, no turno da manhã, da Escola Estadual de Ensino Fundamental e Médio, José Batista de Mello, localizado na cidade de João Pessoa, Paraíba. O conteúdo químico escolhido para o desenvolvimento do conjunto de ações foi estabelecido de acordo com o cronograma do professor regente, sendo determinado separação de misturas.

A metodologia utilizada para a pesquisa foi a qualitativa, a qual segundo André (2013, p. 98) "se fundamentam numa perspectiva que concebe o conhecimento como um processo socialmente construído pelos sujeitos nas suas interações cotidianas, enquanto atuam na realidade, transformando-a e sendo por ela transformados". Também empregou uma pesquisa participante, em que "os sujeitos da pesquisa são considerados coprodutores de conhecimento" (STRECK, 2016, p. 538). E ainda, utilizou-se uma abordagem quantitativa que é caracterizada "pelo emprego da quantificação tanto nas modalidades de coleta de informações quanto no tratamento delas por meio de técnicas estatísticas" (LAKATOS; MARCONI, 2004, p. 269).

Para isso, foram necessárias 10 (aulas) aulas de 30 (trinta) minutos cada, as quais foramfracionadas em quatro partes. A primeira parte (duas aulas) destinou-se a aplicação do Questionário Inicial (QI) com cinco questões sendo uma discursiva e quatro de múltipla escolha sobre a temática "Separação de misturas, com o intuito de investigar os conhecimentos prévios do alunado quanto ao assunto a ser discutido.

A segunda parte (três aulas) dedicou-se a abordagem teórica do conteúdo "Separação de Misturas" por meio de aulas expositivas dialogadas com uso da contextualização como recurso didático. $\mathrm{Na}$ abordagem do tema destacou-se as principais técnicas de separação, o conceito de mistura, os tipos de misturas, definição de solubilidade e as técnicas para separação adequadas para cada tipo de mistura, tais como, para misturas homogêneas: destilação simples ou fracionada, vaporização e liquefação fracionada; para misturas heterogêneas: filtração, decantação, dissolução fracionada, sedimentação e sifonação. Vale salientar que esse segundo momento foi planejado de modo contextualizado a partir dos resultados encontrados na avaliação do QI.

A terceira parte, representada por três aulas, foi caracterizada por aulas experimentais. Para essas, foram necessários os seguintes materiais e reagentes: um funil de bromo fixado em um suporte universal, uma manta elétrica, uma panela de alumínio, um funil simples fixado 
em um suporte universal, filtros de papel, um béquer de $250 \mathrm{~mL}$, um béquer de $100 \mathrm{~mL}$, um béquer de $50 \mathrm{~mL}$, uma proveta de $100 \mathrm{~mL}, 50 \mathrm{~mL}$ de gasolina $\left(\mathrm{C}_{8} \mathrm{H}_{18}\right)$, uma pisseta com água destilada, sal de cozinha $(\mathrm{NaCl})$, areia, e óleo.

Foram realizados três experimentos abordando os processos de separação escolhidos pelo professor regente da turma, os quais foram: filtração, decantação, dissolução fracionada e evaporação. Nesse sentido, o primeiro experimento foi executado com uma mistura heterogênea óleo e água, a qual foi separada por um processo de decantação utilizando o funil de bromo e um béquer de 50mL para coletar o líquido mais denso.

No segundo experimento, uma mistura de água, sal de cozinha $(\mathrm{NaCl})$ e areia foram separados por dissolução fracionada. Para isso, a mistura heterogênea passou por um processo de filtração simples, utilizando funil de vidro, papel filtro e um recipiente para coletar o filtrado. Após a filtração, o filtrado (mistura homogênea) passou por um processo de evaporação, com o uso da manta elétrica, até total passagem da água para o estado de vapor.

O terceiro experimento consistiu em um teste de adulteração que pode ser realizado por um processo de decantação. Para isso, foi utilizado uma mistura heterogênea com $50 \mathrm{~mL}$ de gasolina e $50 \mathrm{~mL}$ de água, a qual foi colocada em uma proveta de $100 \mathrm{~mL}$ e agitada por um tempo. Feito isso, verificou-se se houve variação no volume da gasolina e anotou-se os dados da nova medida para o cálculo de percentagem de tolerância de etanol presente na gasolina, com a intenção de verificar a quantidade de aditivos presente naquela amostra.

Na quarta e última parte (duas aulas), foi realizado a aplicação de um questionário de avaliação, denominado Questionário Final (QF) o mesmo possuía 6 (seis) questões, sendo 3 (três) de múltipla escolha e 3 (três) discursivas, a fim de avaliar e investigar os conhecimentos edificados pelos discentes.

\section{RESULTADOS E DISCUSSÃO}

Frente aos resultados encontrados no Questionário Inicial foi perceptível a falta de conhecimento dos alunos quanto ao tema em estudo, uma vez que mais de $60 \%$ do alunado errou todas as questões dispostas.

A primeira questão do QI (objetiva) solicitava que o discente assinalasse os processos de separação mais adequados para as misturas gasolina-água e nitrogênio-oxigênio. Nesta, foi constatado que apenas $20 \%$ dos alunos assinalaram a resposta correta.

A segunda e a terceira questão tratavam de situações cotidianas, como as etapas de funcionamento do aspirador de pó, as etapas de preparo do café em pó, entre outros. Em ambas, foi solicitado que o alunado marcasse os processos de separação que representassem 
cada etapa. Conforme o analisado, apenas $28 \%$ dos discentes acertaram a segunda questão e $15 \%$ acertaram a terceira questão.

Na quarta questão (subjetiva) foi indagado se há possibilidade de separar uma mistura sal + areia e qual o procedimento a ser feito. A maioria dos discentes não conseguiu edificar uma resposta totalmente correta, porém, cerca de $35 \%$ deles conseguiram elaborar afirmações coerentes. A quinta questão investigou o conceito de fases de uma mistura, em que nesta foram dispostos sistemas heterogêneos para que fosse quantificado o número de fases em cada um deles. Feito a análise, apenas $28 \%$ dos estudantes marcaram a alternativa que representava os números de fases dos sistemas em estudo.

No segundo encontro foram ministradas duas aulas expositivas dialogadas com uso da contextualização, auxiliando na progressão do conteúdo a ser transmitido. Antes de iniciar as aulas foram feitas algumas perguntas sobre: "O que é uma mistura?", "Como se separa uma mistura?", “Quais métodos a serem escolhidos para separar uma mistura?”, “O que é solubilidade?"

Frente aos questionamentos, os alunos não souberam formular repostas adequadas e coerentes. Logo, a equipe buscou ministrar o conteúdo de forma mais interativa a fim de incentivar a participação em sala. Com isso, foi abordado, inicialmente, o conceito formal sobre misturas e seus tipos (homogênea e heterogênea).

De acordo com Reis (2016, p. 51-52), "o conceito de mistura pode ser definido como um material cujo suas propriedades não são constantes mesmo em uma temperatura e pressão constante. As misturas podem ser classificadas como homogêneas e heterogêneas, elas podem apresentar fases e possuírem características específicas”.

A partir dessa abordagem foram iniciadas discussões sobre o contexto, expondo situações e vivências do dia a dia, tais como: mistura heterogênea de água e óleo, mistura homogênea de água e álcool, mistura homogênea de água e sal quando o sal se encontra totalmente dissolvido na solução, dentre outros exemplos. Feito isso, foi explanado a imiscibilidade da água em óleo.

Logo, o docente acrescentou que a imiscibilidade da primeira mistura citada acontece devido a polaridade, das substâncias em estudo, ser diferente, visto que a água é polar e o óleo é composto por ligações C-H (carbono-hidrogênio) que são apolares. No caso da água e álcool, tem-se o álcool que é composto por ligações $\mathrm{C}-\mathrm{H}$, porém apresenta um grupo hidroxila $(\mathrm{OH})$ em sua estrutura, o qual atribui um caráter polar a molécula permitindo ser miscível em água, justificando o motivo de uma ser heterogênea e a outra homogênea.

Aproveitando o mesmo exemplo explicou-se o conceito de solubilidade e como ela 
interferiria no tipo mistura a ser formada. Partindo da afirmação "semelhante dissolve-se e mistura-se com semelhante", as misturas foram classificadas. Além disso, o conceito de separação de misturas foi abordado, expondo sua finalidade e tipos para misturas homogêneas (destilação simples e fracionada, vaporização, liquefação fracionada, centrifugação) e para heterogêneas (filtração, decantação, dissolução fracionada, sedimentação, sifonação, extração).

Para esses, foram apresentados exemplos aplicáveis na cozinha de casa, uma vez que diversas são as técnicas de separação de mistura utilizadas no dia a dia, como por exemplo na preparação do café, utiliza-se o processo de filtração simples para separar o café do pó insolúvel. Outro exemplo é a preparação de um chá em sachê, visto que neste é usado o processo de extração.

Durante a aula surgiram algumas discussões com os alunos, em que eles expressaram: "nós não sabíamos que a solubilidade interferia na escolha do método a ser aplicado para separação", "não conhecíamos que havia tipos de misturas e tantos métodos para ser usados", "nós não sabíamos que em nosso dia a dia tínhamos contato com diversas misturas e fazemos vários processos para separação sem conhecer que tem finalidades específicas para isso". Frente a esse compartilhamento, pode-se perceber a relevância da contextualização dos conhecimentos científicos, pois o alunado consegue compreender a ciência na sua vivência tornando o seu estudo significativo.

No terceiro encontro, aula experimental, percebeu-se que os alunos estavam mais interessados sobre o tema, as práticas escolhidas buscaram relembrar todo conteúdo que foi ministrado com o intuito de demonstrar na prática o que foi abordado teoricamente. Sob esse viés, foram realizados os seguintes experimentos: mistura de água e óleo para descrever o processo de decantação (experimento 1), mistura de sal de cozinha, areia e água para elucidar o processo de filtração/evaporação (experimento 2), e o outro experimento foi a mistura de gasolina e água para o teste de adulteração do combustível demonstrando o processo de decantação. Aparelhagem utilizada na aula prática encontra-se representada na Figura 1 
Figura 1: Equipamentos utilizados para realização dos experimentos. Fonte: Própria.

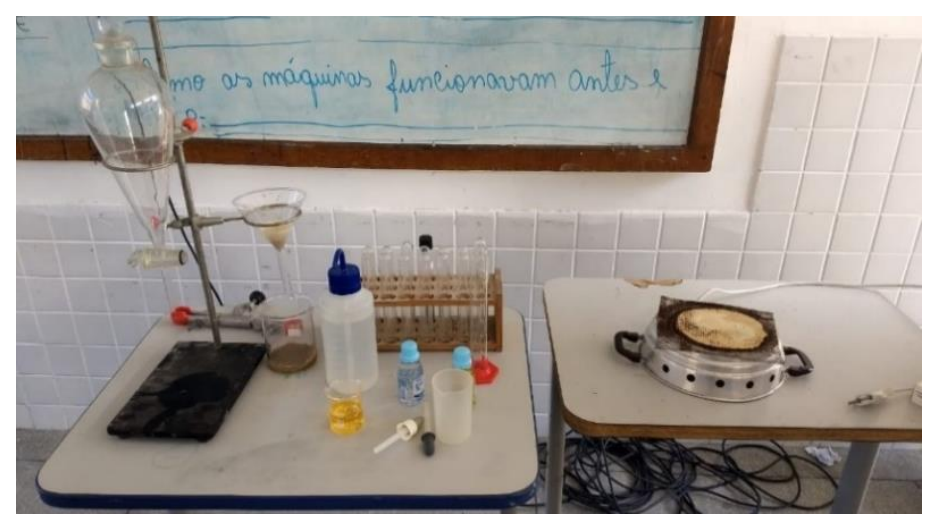

Buscou-se utilizar diversas analogias para que os estudantes conseguissem compreender as definições e fenômenos contidos nos experimentos, através de exemplos reais do dia a dia. No primeiro experimento utilizou-se o funil de decantação, onde colocou-se a água e óleo no funil de bromo e esperou-se sedimentar o líquido com maior densidade (a água). Feito isso, abriu-se a torneira do funil e deixou-se escorrer cuidadosamente toda a água, por ação da gravidade, no béquer de $50 \mathrm{~mL}$ até restar o óleo no funil.

Antes de iniciar a experimentação, foi questionado qual seria a melhor opção para separar dois líquidos imiscíveis como água e óleo, e a maioria dos discentes informou que a decantação seria a mais apropriada, pois o há diferença de densidade. $O$ docente complementou afirmando que oprocesso de decantação é um método físico para separar misturas heterogêneas, seja sólido-líquido ou líquido-líquido imiscíveis. Nesse sentido, o processo de separação, por meio da decantação, pode ser realizado com o funil de bromo, com o intuito de separar os líquidos eficientemente.

No segundo experimento,misturou-se no béquer de $100 \mathrm{~mL}$, a água, areia e o sal de cozinha $(\mathrm{NaCl})$, depois pegou-se o funil simples, o qual foi fixado no suporte universal e o umedeceu com água para fixação do papel de filtro. Em seguida, colocou-se a panela de alumínio sob o funil para captação do líquido filtrado. Após o preparo da mistura, foi questionado aos discentes qual ou quais processos seria ou seriam adequados para separação dos três reagentes envolvidos. Logo, alguns alunos disseram filtração, outros a decantação e evaporação. Os estudantes afirmaram separadamente as técnicas que poderiam ser utilizadas, porém não conseguiram afirmar o passo a passo para separação total dos três reagentes.

Diante disso, iniciou-se a montagem do sistema de filtração simples e a discussão de como faria para separar os três. Feito várias indagações e sugestões, com intuito de incentivar o alunado a pensar na melhor possibilidade, eles conseguiram estabelecer a melhor rota de 
separação para o momento, a qual foi realizar a filtração simples para separar a água + sal da areia, visto que a areia ficaria retida no papel e o sal passaria pelo papel de filtro, uma vez que estava solubilizado em água. E em seguida, iniciar o processo de evaporação para separar toda água do sal, pois apresentam pontos de ebulição diferentes, permitindo que a água seja evaporada completamente e o sal permaneça em seu estado sólido.

Para o terceiro experimento inseriu-se na proveta de $100 \mathrm{~mL}, 50 \mathrm{~mL}$ de gasolina e $50 \mathrm{~mL}$ de água e agitou-se por um tempo. Verificou-se se houve variação no volume da gasolina e anotou-se os dados da nova medida para o cálculo de percentagem de tolerância de etanol presente na gasolina. Visto que o máximo permitido é $25 \%$ de etanol presente, foi verificado de havia adulteração a partir dos novos volumes medidos.

Antes de iniciar a prática perguntou-se aos alunos se eles sabiam como as pessoas faziam para verificar a qualidade do combustível em um determinado posto, e eles não souberam responder. Logo, o docente informou que a gasolina apresenta etanol em sua composição e há um limite para sua composição (25\%), sendo assim, mistura-se água e gasolina para que a proporção de etanol seja conhecida, pois o etanol dissolve-se melhor em água do que em gasolina. Para isso, são adicionados volumes iguais de água e gasolina, os quais são agitados para que o álcool entre em contato com a água e desprenda-se da gasolina que é imiscível em água, e assim possa ser quantificado o volume de etanol presente.

Logo, foi realizado o terceiro experimento (Figura 2) e o volume encontrado após a mistura foi de $62,5 \mathrm{~mL}$ de água + álcool e $37,5 \mathrm{~mL}$ de gasolina, comprovando que a gasolina em estudo não estava adulterada, visto que apresentava $25 \%$ de etanol em sua composição. Diante do exposto, as aulas experimentais, além de coadunar a teoria abordada em sala com a prática, o professor consegue aprimorar a relação docente-discente, amenizando a postura de hierarquia pré-estabelecida culturalmente, o que torna o ambiente mais espontâneo e dinâmico. Segundo Silva (2016, p. 36)

a experimentação se mostra como uma forma de melhorar a compreensão dos alunos sobre os fenômenos, que muitas vezes se explicados em uma aula convencional, não surtiria o mesmo efeito. Ou seja, a utilização de modelos nos remete ao abstrato para entender o concreto, o que se torna um desafio muito grande, tanto para o professor quanto para o aluno. 
Figura 2: Momento do teste de adulteração. Fonte: Própria.

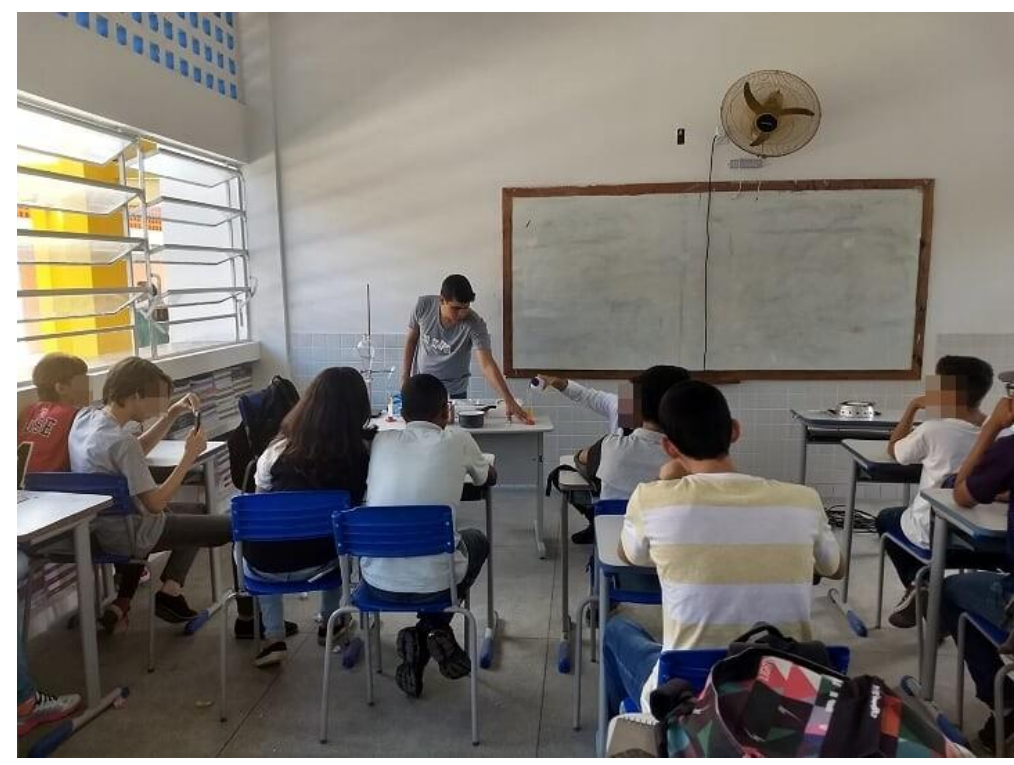

Na última parte desse estudo houve a aplicação do Questionário Final, no qual haviam seis questões, em que três foram subjetivas buscando investigar a capacidade de arguição dos discentes e as outras três foram objetivas. As questões objetivas foram abordadas de forma contextualizada e foi denotado que mais de $85 \%$ do alunado conseguiu assinalar as respostas corretas. Quanto as indagações subjetivas, mais de $87 \%$ dos discentes conseguiram sugerir e discutir os processos de separação mais adequados para os sistemas em estudo, bem como estabelecer discussões para cada tipo de processo.

Diante do exposto, o conjunto de ações proposto aliado as ferramentas didáticas (contextualização e experimentação) propiciaram um âmbito educacional dinâmico, em que os discentes puderam partir de suas hipóteses, interação aluno-aluno e professor-aluno para construir um conhecimento químico significativo. Com isso, o docente deixa de ser um ditador e passa a ser um mediador de informações no processo de ensino-aprendizagem, promovendo a estruturação de seres pensantes e críticos.

\section{CONCLUSÕES}

Essa ação conseguiu demonstrar que a adoção de aulas contextualizadas com uso da experimentação permite viabilizar um processo de ensinoaprendizagem em Química de modo mais significativo. O Ensino de Química pode contribuir de forma decisiva, se ofertado com qualidade utilizando não apenas teorias, mas ferramentas educacionais que promovam incentivar a curiosidade do aluno, diminuindo os níveis de déficit de atenção e aprendizagem. Isso é denotado, principalmente em aulas experimentais, visto que nessas, o docente aproxima sua relação com o discente elaborando situações problemáticas, despertando a curiosidade e 
motivando-o a participar da construção do conhecimento nesse momento. Logo, o aprendizado se torna significativo e o discente se torna capaz de julgar e avaliar os fenômenos que envolve seu dia a dia.

\section{REFERÊNCIAS}

ANDRÉ, Marli E.D.A. Educação e Contemporaneidade.Revista da FAEEBA, v. 22, n. 40, p. 95-103, 2013

BRASIL (País) Secretaria de Educação Média e Tecnológica - Ministério da Educação e Cultura. Parâmetros Curriculares Nacionais do Ensino Médio. Brasília: MEC/SEMTEC, 1999.

FREIRE, P. Pedagogia do Oprimido. 50ª ed. Rio de Janeiro: Paz e Terra, 2011.

LAKATOS, E. M.; MARCONI, M. A. Metodologia Científica. 4ª ed. São Paulo: Atlas, 2004.

LUIZ, W., PACHECO, R. Educação em Química. São Paulo: Unijuí, 1997.

OLIVEIRA, L. M. S.; SILVA, O. G.; FERREIRA, U. V. S. Desenvolvendo jogos didáticos para o ensino de química. HOLOS, 2011, v. 5, p.166 - 175. Disponível em:

<http://www2.ifrn.edu.br/ojs/index.php/HOLOS/article/view/567>. Acesso em: 14 Set 2018.

OLIVEIRA, R.; CACURO, T. A.; FERNANDEZ, S.; IRAZUSTA, S. P. Aprendizagem Significativa, Educação Ambiental e Ensino de Química: Uma Experiência Realizada em uma Escola Pública.Revista Virtual de Química, v. 8, nº 3, p. 913-925, 2016.

REIS, Martha. Químicavol.1. São Paulo: Editora Ática, 2016

SILVA, V. G. A importância da experimentação no ensino de química e ciências. Trabalho de Conclusão de Curso - TCC. Universidade Estadual Paulista. Bauru, 2016.

STRECK, D. R. Metodologias participativas de pesquisa e educação popular: reflexões sobre critérios de qualidade. Revista Interface: Comunicação, Saúde, Educação, vol. 20, n. 58, p. 537-547, 2016. 